\title{
Revisiting Cystic Lung Disease - A Review on Diagnostic Approach in High Resolution Computed Tomography Thorax
}

\author{
Rajoo Ramachandran ${ }^{1}$, Jeffrey Ralph ${ }^{2}$, Rajeev Pulimi³, Logesh Rajamani ${ }^{4}$, Prabhu Radhan ${ }^{5}$, Kumaresh Athiyappan ${ }^{6}$ \\ 1,2,3,4,5, 6 Department of Centre of Excellence in Radiology and Imaging Sciences (CERIS), Sri Ramachandra Institute of \\ Higher Education and Research Institute (Deemed to Be University), Chennai, Tamil Nadu, India.
}

\section{ABSTRACT}

The differential diagnosis of the cystic lung disease is extensive, ranging from an isolated incidental lung cyst to multiple diffuse lung cysts with other varied associated lung abnormalities. High resolution computed tomography (HRCT) thorax is the imaging modality of choice in the evaluation of these diseases, by improving the characterisation of the lung cysts (number, size, shape, distribution, wall thickness and regularity), and associated pulmonary and extrapulmonary abnormalities (like ground glass densities, nodules, interstitial fibrosis, mediastinal lymphadenopathy). After differentiating from the common cyst mimickers (cavity, centrilobular emphysema and cystic bronchiectasis), they should be grouped by location into subpleural cysts (paraseptal emphysema, bulla and honeycombing) and intraparenchymal cysts. Intraparenchymal cysts are in turn categorised into solitary / localised cysts (incidental cyst, congenital pulmonary airway malformations, intrapulmonary bronchogenic cyst and hydatid cyst) and multiple diffuse cysts. The next step will be the categorisation of these multiple diffuse cysts into those without other lung abnormalities (lymphangioleiomyomatosis and Birt-Hogg-Dube syndrome) and those with other lung abnormalities such as predominant ground glass densities (Pneumocystis jirovecii pneumonia, desquamative interstitial pneumonia, lymphoid interstitial pneumonia, subacute hypersensitivity pneumonitis and pneumatoceles) or predominant nodules (pulmonary Langerhans cell histiocytosis, amyloidosis, light chain deposition disease, follicular bronchiolitis, recurrent respiratory papillomatosis, cystic tuberculosis, cystic lung metastasis, sarcoidosis, and pulmonary mesenchymal cystic hamartomas). We conclude that this orderly radiologic approach in a given HRCT chest study of a cystic lung disease (in addition to correlation with clinical and laboratory findings), can lead us to a specific diagnosis in majority of instances, thereby optimising their treatment management, without the need of an invasive biopsy.

\section{KEY WORDS}

HRCT Thorax, Lung Cysts, Ground Glass Densities, Lung Nodules
Corresponding Author:

Dr. Logesh Rajamani,

Department of Centre of Excellence

in Radiology and Imaging Sciences (CERIS), Sri Ramachandra Institute of Higher Education and RESEARCH Institute (Deemed to Be University), Chennai, Tamil Nadu, India. E-mail: logeshsr18@gmail.com

DOI: $10.14260 / j e m d s / 2021 / 302$

How to Cite This Article:

Ramachandran R, Ralph J, Pulimi R, et al. Revisiting cystic lung disease - a review on diagnostic approach in high resolution computed tomography thorax. J Evolution Med Dent Sci 2021;10(19):1435-1443, DOI: 10.14260/jemds/2021/302

Submission 09-11-2020,

Peer Review 11-03-2021,

Acceptance 17-03-2021,

Published 10-05-2021.

Copyright (C) 2021 Rajoo Ramachandran et al. This is an open access article distributed under Creative Commons Attribution License [Attribution 4.0 International (CC BY 4.0)] 


\section{BACKGROUND}

Lung cysts are defined as well-defined air containing lesions (rarely containing fluid or solid components) with thin (1-3 $\mathrm{mm}$ ) perceptible walls, the walls being fibrous or epithelial in nature. ${ }^{1}$ There is a broad spectrum of conditions or diseases characterised by lung cysts and hence, stepwise approach is necessary to arrive at a specific diagnosis. Although cysts can occur commonly in the lung diseases like Langerhans cell histiocytosis, lymphangioleiomyomatosis and lymphoid interstitial pneumonia, cysts can also occur rarely in many other lung diseases.

Any cystic lung disease can be complicated by spontaneous pneumothorax and present clinically with acute dyspnoea; otherwise, most of the non-infective cystic lung disease usually present with nonspecific symptoms such as chronic cough and dyspnoea. High resolution computed tomography thorax is the imaging modality of choice for the evaluation of these cystic lung diseases.

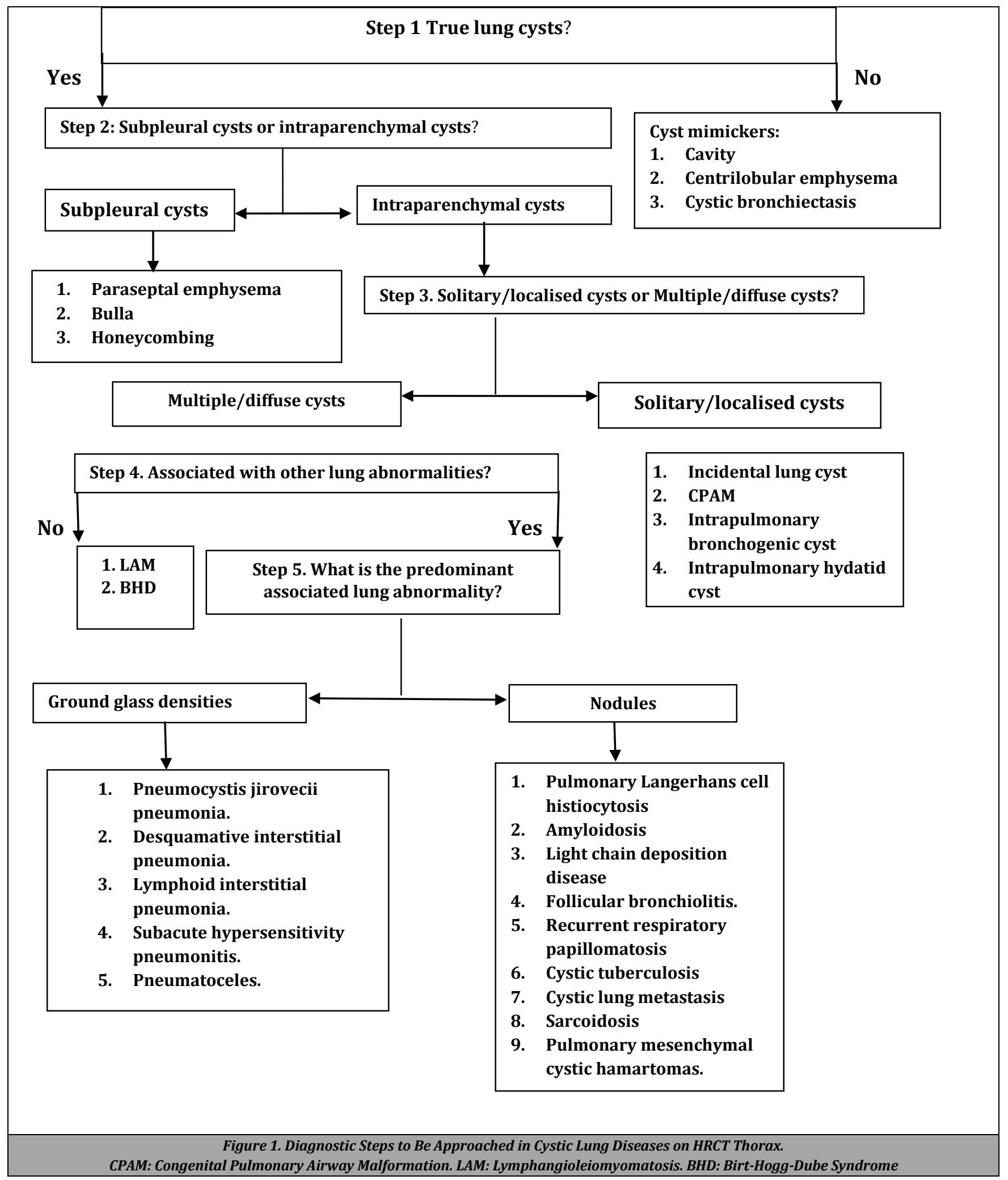


First of all, it is important to differentiate lung cysts from air containing cyst like lesions such as cavities, cystic bronchiectasis and centrilobular emphysema. ${ }^{2}$ Computed tomography (CT) features of cysts (like number, location, and distribution) and associated lung abnormalities (like nodules, ground glass densities, septal thickening), along with clinical and laboratory features, may aid in differentiating different diseases characterised by lung cysts. ${ }^{3}$ Occasionally, biopsy may still be necessary in reaching the final specific diagnosis. Awareness of the different conditions producing lung cysts and their imaging features is therefore essential for the correct diagnosis and treatment of these patients.

The purpose of this review is to elaborate the different orderly steps (Figure 1) which are to be followed while analysing the HRCT thorax scan, in order to reach a more specific diagnosis of the cause of cystic lung disease.

\section{DIFFERENTIATING LUNG CYSTS} FROM CYST-LIKE LESIONS

This is the first step in the diagnostic approach to cystic lung diseases.

\section{Cavity}

It is an air-filled lesion with a relatively thick and irregular wall ( $>3 \mathrm{~mm}$ ), and usually occur as a result of necrosis in a nodule, mass or consolidation (could be infective or non-infective granulomatous or malignant in aetiology). Some cavitary lesions may become thin walled in the late stage and can mimic lung cysts with thin walls ( 1 to $3 \mathrm{~mm})_{.1,2,4}$

\section{Centrilobular Emphysema}

They are usually multiple in number and sub centimetric in size with no perceptible wall and many of them may have a central dot (representing a centrilobular artery in the center of a secondary pulmonary lobule); in the late stages, these sub centimetric air-filled lesions may become confluent and inseparable from each other (appearing as multiple large illdefined areas of low attenuation, with diffuse thinning of the intervening vessels). They are predominately seen in the upper lobes, with subpleural sparing and are usually associated with cigarette smoking. ${ }^{2,5,6}$

\section{Cystic Bronchiectasis}

This dilated airway disease usually mimic lung cysts when viewed in cross section but can be easily distinguished from the lung cysts by finding their tubular (rather than spherical dimension) and branching pattern on contiguous axial CT images or on coronal / sagittal CT reformations. They are associated with bronchial wall thickening, fibrotic atelectasis, air trapping and rarely intraluminal air-fluid levels. They are usually clustered (giving a bunch of grapes appearance, when aggregated in later stages) and can extend up to the pleural surface..$^{1,7}$

\section{ARE THESE CYSTS SUBPLEURAL OR} INTRAPARENCHYMAL IN LOCATION?

After differentiating the true cysts from cyst mimickers, the next step is to see whether these cysts are completely surrounded by the lung parenchyma (intraparenchymal cysts) or not; completely surrounded by the lung parenchyma but abutting the pleura on at least one of its surfaces (subpleural cysts).

\section{Subpleural Cysts \\ Paraseptal Emphysema}

They are almost always subpleural (single layer along pleural surface) and usually sub centimetric in size. They are more elongated than spherical in dimension and are usually multiple with bilateral symmetric distribution. They are predominantly seen in the upper lobes (more commonly along the dorsal surface) and are often associated with mild adjacent fibrosis. They are usually seen isolated in the young adults but are often associated with centrilobular emphysema in older patients. The patients usually remain asymptomatic but may present as spontaneous pneumothorax in young adults (as with any other cystic lung disease).1,5,6

\section{Bulla}

They have similar radiologic appearance with paraseptal emphysema but are larger in size (more than $1 \mathrm{~cm}$ ) and are usually with more poorly perceptible wall $(<1 \mathrm{~mm}$ thickness) and hence, can mimic pneumothorax, when large in size (as they are often subpleural in location like paraseptal emphysema). They are typically larger in the lung apices, and it can be called a giant bulla when it occupies at least one third of the hemi-thoracic volume. Although paraseptal emphysema is the most common cause, it may also be seen along with centrilobular emphysema. ${ }^{1,6,8}$

\section{Honeycombing}

They usually appear as multiple stacked layers of thick-walled (1 to $3 \mathrm{~mm}$ ) subpleural cysts (with shared walls) and are sub centimetric in size (but occasionally can be in single layer and larger in size up to $2.5 \mathrm{~cm}$ ). They are usually associated with other imaging features of pulmonary interstitial fibrosis (such as reticulations, architectural distortion and tractional bronchiectasis) and are considered as a marker of irreversible interstitial fibrosis. They are most commonly seen in usual interstitial pneumonia (UIP) and is a specific finding for the UIP pattern, if it involves more than $8 \%$ of the lung volume. They are predominantly seen in the basal segments of lower lobes but can be seen with upper lobar predominance in few chronic interstitial lung diseases like sarcoidosis, chronic hypersensitivity pneumonitis etc. 9,10

\section{SOLITARY / LOCALIZED CYSTS OR MULTIPLE / DIFFUSE CYSTS}

As a third step, the intraparenchymal cysts are then categorised into whether they are solitary / localised cysts (single cyst or multiple cysts in a localised lung region) or multiple / diffuse cysts (multiple cysts distributed in different lobes of the bilateral lungs). 


\section{Solitary or Localised Cysts}

\section{Incidental Lung Cysts}

They are usually not seen below 40 years of age and their prevalence increases proportionately with increasing age, commonly single or few in number, and usually seen in the peripheral and basal aspect of the lungs. So, they likely represent a sequela of normal ageing process; less likely, they may represent a persistent remnant of the old infection or trauma, or initial manifestation of any other disease process, or may indicate a small focus of congenital lobar emphysema. Hence older patient age, fewer number of cysts in the basal lung regions and absence of other CT lung abnormalities are helpful in differentiation of these incidental cysts from other disease processes. 3,11

\section{Congenital Pulmonary Airway Malformation (CPAM)}

Although this common congenital lung malformation (abnormal hamartomatous bronchial proliferation) usually presents in neonate with progressive respiratory distress, they can remain asymptomatic until later, with recurrent chest infections as the usual presentation in the young adults (with male predominance). They are usually seen as multiple confluent thin-walled air-filled cysts of variable sizes (small to large), with or without air-fluid levels in the cysts. In the most common form of the disease, one or few large dominant cysts may be seen in the center, with multiple smaller cysts surrounding them. They are usually unilateral and confined to a single lung segment or lobe. They may rarely be seen in association with sequestration (another congenital lung malformation which usually appears on imaging as mass like consolidation having systemic arterial supply) as hybrid lesions. 3,12 (Figure 2).

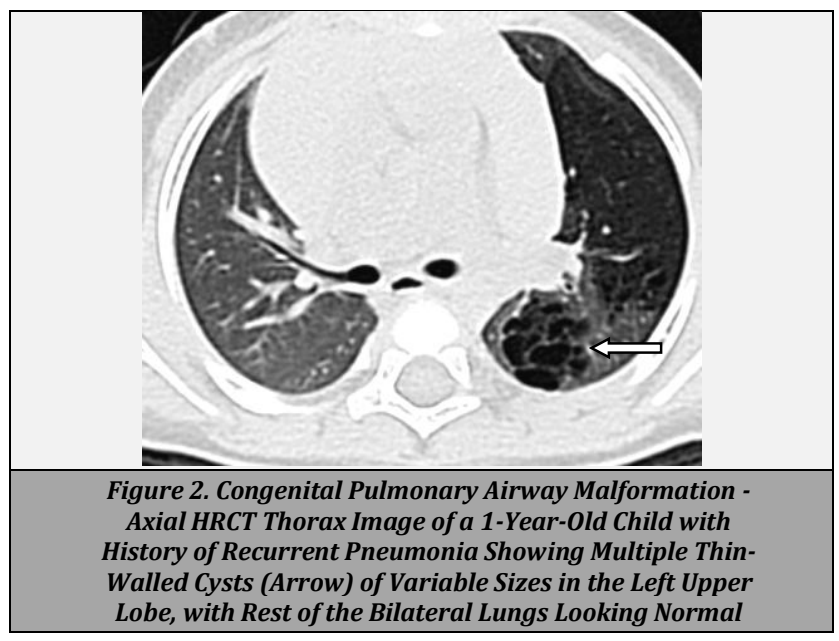

Intrapulmonary Bronchogenic Cyst

They are usually seen as a well-defined large fluid filled solitary unilocular cyst, with air filled cyst being rare (because unlike CPAM, these cysts do not usually communicate with the bronchial airway). They are commonly located in lower lobe and typically perihilar. They are usually spherical in shape with smooth or lobulated margin. When seen rarely with airfluid levels (due to acquired bronchial communication or a superadded infection), clinical features and previous chest HRCT or radiographic images may be helpful in differentiating them from the lung abscess (which are usually characterised by thick wall, irregular inner surface of the wall, with groundglass densities or consolidations in the surrounding lung parenchyma) or infected bulla. Clinically patient may be asymptomatic or may present with features of recurrent chest infection or chronic respiratory distress (due to airway obstruction by the mass effect of the cyst). ${ }^{12,13}$

\section{Intrapulmonary Hydatid Cyst}

They are usually solitary and fluid-filled but can be multiple and air-filled rarely. Commonly seen in the lower lobes. Usually appears larger in size and spherical or oval in shape with relatively hyperdense wall and hypodense fluid content. Ruptured hydatid cyst may communicate with the bronchus and may show features such as air crescent sign (crescent shaped air among the fluid content), onion peel sign (rim of air seen between the wall and the fluid content), water lily sign (thick floating membranes within the fluid content) or consolidations around the cyst. When the cyst ruptures and communicate with bronchioles, patients usually cough out grape-skin like material; otherwise unruptured intrapulmonary hydatid usually presents clinically with insidious cough and chest pain. ${ }^{14,15}$

\section{Multiple Diffuse Cysts with Other CT Lung Abnormalities}

As a fourth step, multiple diffuse type intraparenchymal cysts are further sub categorised into whether they are seen as an isolated lung abnormality or associated with other lung abnormalities like ground glass densities, nodules, septal thickening etc.

\section{Multiple Diffuse Cysts as an Isolated Lung Abnormality \\ Lymphangioleiomyomatosis (LAM)}

This is a rare disease, almost exclusively affecting the women of reproductive age, with gradually worsening dyspnoea and most patients die within 10 years of the onset of symptoms. Although it can occur sporadically, it is more commonly associated with tuberous sclerosis (neurocutaneous syndrome with autosomal dominant inheritance). Lung cysts occurs in $100 \%$ of the patients with LAM. Typically, the cysts are numerous, well defined, thin walled, scattered diffusely and symmetrically in bilateral lungs (but may spare the extreme lung apices), round to oval in shape and sub centimetric in size (rarely larger than $3 \mathrm{~cm}$ ). Although lung parenchyma between the cysts are typically normal, rarely these cysts may be associated with small centrilobular nodules, patchy ground-glass densities or interlobar septal thickening. LAM may present with extrapulmonary findings on HRCT thorax, such as chylous pleural effusion and dilated thoracic duct (occurring due to lymphatic obstruction), sclerotic focal lesions in the bony thoracic cage or pneumothorax (as a common complication from the numerous lung cysts).16,17 (Figure 3).

\section{Birt-Hogg-Dube Syndrome (BHD)}

This is a very rare familial autosomal dominant disease characterised by the family history of recurrent spontaneous 
pneumothoraxes, renal tumours, skin fibrofolliculomas and colonic polyposis. Like incidental cysts, they are also commonly seen in the peripheral and basal aspect of the lungs, and in addition, they are more prone to occur in the medial aspects of the lungs (para mediastinal). These cysts are usually multiple, thin walled, variable in shape (predominately elongated) and may rarely be seen with bullous emphysema. Since BHD shares many features with LAM such as lung cysts with intervening normal lung parenchyma, spontaneous pneumothorax, renal tumours and skin lesions, differentiation between these two entities may be problematic: but characteristics of cysts in the BHD such as fewer cyst number, zonal predominance of cysts (peripheral, basal, para mediastinal) and larger cyst size may help in ruling out LAM (characterized by numerous cysts showing no zonal predominance and sub centimetric in size) as the possible cause. ${ }^{18,19}$

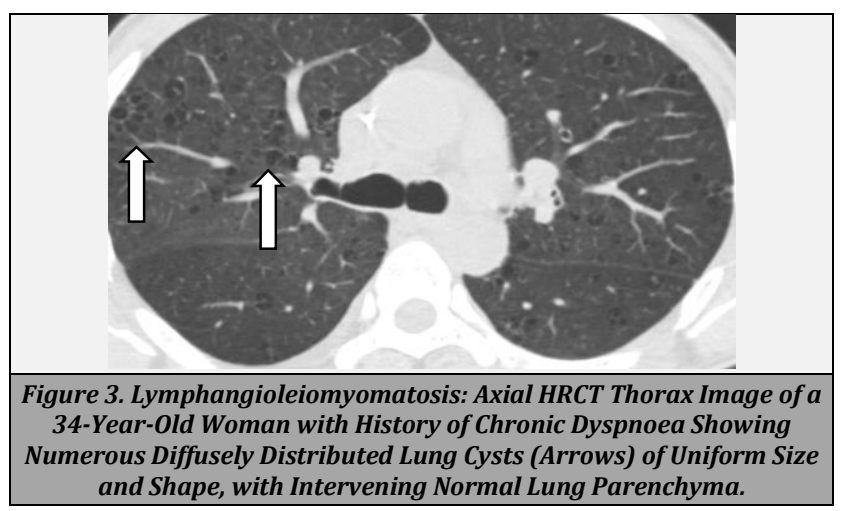

\section{WHAT IS THE PREDOMINANT CT LUNG ABNORMALITY ASSOCIATED WITH THESE MULTIPLE DIFFUSE CYSTS?}

The final step is to identify the predominant CT lung abnormality associated with these multiple diffuse cysts: whether ground glass densities or nodules.

\section{Multiple / Diffuse Cysts with Ground Glass Densities (Table 1)}

Pneumocystis Jirovecii Pneumonia (PCP)

PCP is a fungal pneumonia, almost exclusively affecting the immunocompromised patients (with CD4 counts $<200$ cells $\mathrm{mm}^{3}$ ), with nonspecific insidious symptoms like cough and dyspnoea (with or without fever) as the usual clinical presentation. Most common lung abnormality is the presence of bilateral symmetrically distributed patchy or diffuse ground glass densities, predominantly in the perihilar regions (upper lobe predominance seen in those receiving aerosolised prophylactic therapy for PCP whereas lower lobe predominance seen in those without the prophylactic medication). Multiple bilateral lung cysts (within these ground glass areas) are seen approximately in $1 / 3^{\text {rd }}$ of these patients, and they are usually variable in size, shape and wall thickness. The ground glass areas may also show interlobular septal thickening, leading to crazy-paving pattern. Atypical features like lung consolidations, centrilobular lung nodules, pleural effusion or mediastinal lymphadenopathy may be seen in patients receiving prophylactic therapy for PCP.20,21 (Figure 4).

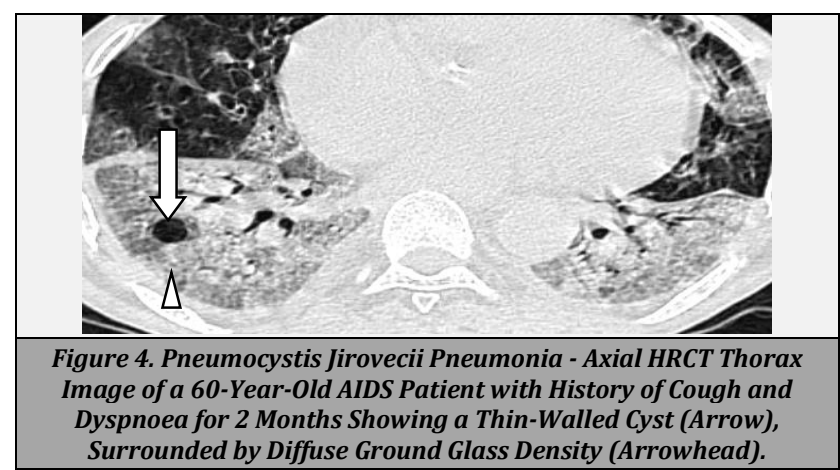

Desquamative Interstitial Pneumonia (DIP)

Although this uncommon interstitial lung disease usually occurs in association with heavy smoking, it can also occasionally occur in patients with certain toxin inhalations, drugs, autoimmune diseases or viral illnesses.

It usually affects the middle-aged patients with progressive dyspnoea, chronic non-productive cough. On HRCT thorax, it usually manifests as bilateral symmetrically distributed diffuse ground glass densities (occasionally having granular or nodular texture), predominantly in the peripheral aspect of the basal lung regions; these ground glass densities may also be having foci of irregular linear densities (reticulations). In $1 / 3^{\text {rd }}$ of these patients, multiple well defined thin walled small (usually less than $2 \mathrm{~cm}$ ) cysts are seen scattered within these ground glass densities. In late stages, DIP may also show cysts of honeycombing (indicating irreversible interstitial fibrosis) and cyst-like centrilobular emphysema (another smoking related abnormality).22,23

\begin{tabular}{|c|c|c|c|}
\hline Diagnosis & Clinical Features & Lung Cyst Features & Other Lung Abnormalities \\
\hline $\begin{array}{l}\text { Pneumocystis jirovecii } \\
\text { pneumonia }\end{array}$ & $\begin{array}{l}\text { Immunocompromised patients with insidious cough and dyspnoea; } \\
\text { may or may not present with fever. }\end{array}$ & $\begin{array}{l}\text { Multiple cysts of variable size, } \\
\text { shape and wall thickness, seen in } 1 \\
\text { / } 3^{\text {rd }} \text { of patients }\end{array}$ & $\begin{array}{l}\text { Bilaterally symmetric, patchy or diffuse ground glass } \\
\text { densities, with perihilar predominance }\end{array}$ \\
\hline $\begin{array}{l}\text { Desquamative } \\
\text { interstitial } \\
\text { pneumonia }\end{array}$ & $\begin{array}{l}\text { Usually associated with smoking, occasionally with toxin inhalations, } \\
\text { drugs, autoimmune or viral diseases. Middle aged patients with } \\
\text { chronically progressive cough and dyspnoea. }\end{array}$ & $\begin{array}{l}\text { Multiple small round cysts seen in } \\
1 / 3^{\text {rd }} \text { of patients. }\end{array}$ & $\begin{array}{l}\text { Bilaterally symmetric, patchy or diffuse ground glass } \\
\text { densities, with basal and peripheral predominance }\end{array}$ \\
\hline $\begin{array}{l}\text { Lymphoid interstitial } \\
\text { pneumonia }\end{array}$ & $\begin{array}{l}\text { Insidious cough and dyspnoea in patients with various disorders such } \\
\text { as connective tissue disorders (like Sjogren syndrome), HIV infection, } \\
\text { systemic lupus erythematosus etc. }\end{array}$ & $\begin{array}{l}\text { Few variable sized cysts seen in } 2 / \\
3^{\text {rd }} \text { of patients, with peripheral and } \\
\text { basal predominance. }\end{array}$ & $\begin{array}{c}\text { Bilaterally symmetric, diffuse ground glass densities } \\
\text { and ill-defined centrilobular nodules; perilymphatic } \\
\text { pattern abnormalities (like interlobular septal } \\
\text { thickening). }\end{array}$ \\
\hline $\begin{array}{l}\text { Sub-acute } \\
\text { hypersensitivity } \\
\text { pneumonitis }\end{array}$ & $\begin{array}{l}\text { History of exposure to inciting agents (organic particles to drugs). } \\
\text { Mild fever, cough and dyspnoea worsening over few weeks or months. }\end{array}$ & $\begin{array}{l}\text { Few randomly distributed small } \\
\text { cysts seen in only } 10 \% \text { of patients. }\end{array}$ & $\begin{array}{l}\text { Bilaterally symmetric, diffuse ground glass densities, } \\
\text { areas of air trapping (giving mosaic attenuation) } \\
\text { and ground-glass centrilobular nodules. }\end{array}$ \\
\hline Pneumatoceles & $\begin{array}{l}\text { Usually occurring as a result of pneumonia, trauma or hydrocarbon } \\
\text { aspiration. }\end{array}$ & Few transient, round, cysts. & $\begin{array}{l}\text { Ground glass densities or consolidations (features of } \\
\text { the pneumonia or lung contusion) surrounding the } \\
\text { cysts. }\end{array}$ \\
\hline
\end{tabular}




\section{Lymphoid Interstitial Pneumonia (LIP)}

This uncommon benign lymphoproliferative disease usually occurs in association with various disorders such as connective tissue disorders (like Sjogren syndrome), human immunodeficiency virus (HIV) infection, Castleman disease and autoimmune diseases (like systemic lupus erythematosus, Hashimoto`s thyroiditis and primary biliary cirrhosis). It commonly affects the middle- aged patients with insidious onset of cough and dyspnoea, with or without systemic symptoms like fever, night sweats and arthralgia. Most common CT findings include diffuse ground glass densities and scattered small centrilobular ground glass nodules; they may be seen along with cysts and perilymphatic pattern abnormalities (interlobular septal thickening, peri bronchovascular bundle thickening, small subpleural nodules and mediastinal lymphadenopathy). These lung cysts, occurring in $2 / 3^{\text {rd }}$ of these patients, are usually thin walled, variable sized (usually $<3 \mathrm{~cm}$ ), typically fewer in number (as compared to LAM and LCH) but distributed diffusely with peripheral, perivascular and basal lung predominance. In most cases, ground-glass densities resolve with time, and lungs cyst may be the only residual finding in chronic cases of LIP. Hence, isolated presence of few scattered lung cysts in patients with Sjogren syndrome, most likely indicate the diagnosis of LIP. 24,25

Subacute Hypersensitivity Pneumonitis (Sub-Acute Extrinsic Allergic Alveolitis)

This diffuse granulomatous inflammatory lung disease is caused by the intermittent or continuous exposure of wide variety of instigating agents, from organic particles to drugs (but the precipitating agent is often not obvious in the clinical history) and usually presents clinically with mild fever, cough and dyspnoea worsening over few weeks or months or may be characterized by recurrent episodes of acute fever, cough and chest pain, on the background of gradually worsening dyspnoea. Classic imaging findings include diffuse bilaterally symmetric ground glass densities (but sometimes patchy and concentrated in the upper and mid lungs), areas of air trapping (giving mosaic attenuation) and centrilobular ground glass nodules. Lung cysts are seen in only $10 \%$ of these patients and are typically few in number and small in size with random distribution. If the exposure to the inciting agent is not stopped by the early diagnosis, they are likely to progress into chronic hypersensitivity pneumonitis stage (with irreversible changes of fibrosis). ${ }^{26,27}$

\section{Pneumatoceles}

It represents transient, thin walled, round cysts, occurring as a result of pneumonia, trauma or hydrocarbon aspiration. In the early stages, it may be accompanied by the surrounding ground glass density or consolidation (features of the pneumonia or lung contusion) and it usually resolves within six weeks (but occasionally persist and can present as an incidental lung cyst). In contrast to the lung abscess (another complication of the pneumonia), its wall appears thin and regular, with smooth inner margin, and little fluid content, if any. ${ }^{28,29}$ Findings that are helpful in differentiating the various cystic lung diseases with ground glass densities as the other predominant associated CT lung abnormality are shown in Table 1.

\section{Multiple / Diffuse Cysts with Lung Nodules}

Pulmonary Langerhans Cell Histiocytosis (LCH)

This rare interstitial lung disease usually affects the young adults with chronic dyspnoea, non-productive cough and weight loss, exclusively affecting the cigarette smokers. In the early stages, LCH presents typically with small sized (subcentemetric), irregularly shaped (stellate) centrilobular (less commonly peri bronchovascular) nodules, showing bilaterally symmetric distribution with upper and middle lung predominance and typical sparing of the costophrenic angle regions and medial paracardial tip regions. These nodules cavitate later to form thick-walled cavities and ultimately thin walled round to oval cysts. These cysts in turn later coalesce to form bizarre shapes (like bi-lobed, clover leaf like, septate, or branching patterns resembling bronchiectasis). Like the stellate nodules, the cysts are usually subcentimetric in size but may be large, measuring up to $2 \mathrm{~cm}$. LCH may show ground glass densities like desquamative interstitial pneumonia (DIP), another smoking related cystic lung disease (but DIP usually associated with centrilobular emphysema without any lung nodules). Temporal heterogeneity of the lesions (small sized stellate centrilobular nodules, thick-walled cavities and thinwalled round to bizarre, shaped cysts) is typically seen in $\mathrm{LCH}$, and such characteristic appearance with sparing of lung base in a young smoker can clearly point out the diagnosis of LCH. ${ }^{30,31}$

\section{Amyloidosis}

It is a rare multisystem disease, with pulmonary involvement of amyloidosis being rarer. Among pulmonary amyloidosis, presence of the lung cysts is even rarer and are most often seen in association with localised amyloidosis caused by Sjogren syndrome and MALT lymphoma. Usually, pulmonary amyloidosis presents with vague symptoms like chronic dyspnoea and non-productive cough. The cysts are usually multiple, thin walled, round to lobulated in shape, of varying sizes, peripheral (less likely peri bronchovascular) in location, predominantly in the lower lobes, and frequently associated with small to large lung nodules (many showing calcifications). Other less commonly associated HRCT thorax findings include ground glass densities and interlobular septal thickening in the lungs, tracheal wall thickening, and mediastinal lymphadenopathy. 32,33

\section{Light Chain Deposition Disease}

It is a rare multisystem disease, commonly affecting the kidneys, followed by the liver and heart, with pulmonary involvement being even more rare. It usually occurs in the middle-aged patients with plasma cell dyscrasias (like multiple myeloma) and less commonly in patients with autoimmune disease. Like amyloidosis, it also usually presents with vague symptoms like chronic dyspnoea and nonproductive cough. Pulmonary involvement usually manifests with multiple, small sized (usually 5 to $15 \mathrm{~mm}$ ), thin walled, round cysts, and are diffusely scattered in bilateral lungs. Lung cysts are commonly associated with multiple, diffusely scattered, small to large sized, irregularly shaped lung nodules and mediastinal lymphadenopathy. ${ }^{32,34}$

\section{Follicular Bronchiolitis}

This uncommon benign lymphoproliferative disease affecting the small airway (in contrast to the lymphoid interstitial 
pneumonia affecting the lung interstitium), usually occurs in patients with underlying collagen vascular diseases or immunodeficiency diseases. It usually affects children with chronic cough and dyspnoea, and recurrent upper respiratory infections. Most commonly, this disease manifests diffuse centrilobular ground glass nodules (may also show peribronchial nodules) but may predominantly involve the peripheral aspect of the lower lobes, with or without areas of air-trapping, tree-in-bud nodules and patchy ground glass densities. Few small thin-walled scattered lung cysts can be an uncommon manifestation. ${ }^{35,36}$

\section{Recurrent Respiratory Papillomatosis}

With human papilloma virus as the causative agent, it manifests as development of multiple small squamous papillomas in the respiratory epithelium, most commonly in the larynx (most common benign tumour of the larynx in children), followed less commonly by tracheobronchial involvement. It usually affects children with chronic hoarseness, stridor and respiratory distress but can also present late in adults (bimodal age presentation). It rarely involves the pulmonary parenchyma producing multiple thinwalled cysts of variable sizes, surrounded by small to large nodules (may show cavitation), with posterior lung predilection (due to gravity). Distal airway obstruction by these papillomas may lead to foci of peripheral atelectasis and bronchiectasis (with or without mucous plugging). ${ }^{37,38}$

\section{Cystic Tuberculosis (TB)}

Multiple thin walled, irregularly shaped (due to associated fibrosis), variable sized lung cysts (predominantly in the upper and mid lung zones) are one of the rare manifestations of the pulmonary TB (presenting with clinical features of chronic cough, fever and weight loss); these rare manifestations of the pulmonary TB usually occur in individuals with immunocompromised status, older age, autoimmune disease, diabetes mellitus, alcoholism and malnourishment. These lung cysts are commonly seen along with centrilobular nodules (often with tree-in-bud pattern) and bronchiectasis (cystic or tubular); may also be seen associated with ground-glass densities or consolidations.

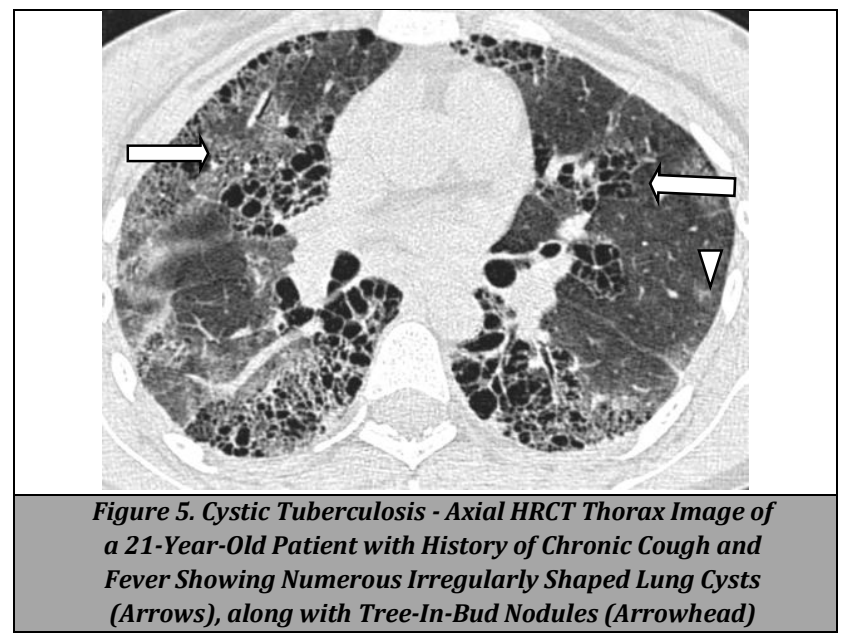

These cysts are seen to resolve with the resolution of the lung nodules and ground-glass densities after anti- tuberculous treatment in most of the cases but may be seen as persistent lung cysts in few of these cases. ${ }^{39,40}$ (Figure 5).

\section{Cystic Lung Metastasis}

Very rarely, lung metastasis may present as multiple thinwalled cysts, in patients with history of primary malignancies elsewhere (more commonly in primary epithelial malignancies and angiosarcomas). As with other lung metastasis, the cysts tend to predominate in the peripheral aspect and lower lung zones and are of variable sizes and wall thickness. These cysts may be associated with lung nodules (may be with internal haemorrhage in case of angiosarcoma primaries); occasionally air-fluid levels may be seen within the thin-walled cysts (due to internal haemorrhage). New lung cysts in a patient with known primary malignancies elsewhere are most likely to be cystic lung metastasis. ${ }^{41,42}$

\section{Sarcoidosis}

Pulmonary sarcoidosis may present with respiratory symptoms such as chronic cough and dyspnoea or patients may present with skin abnormalities (like erythema nodosum, plaques, scars), without respiratory symptoms. Few thin walled irregularly shaped cysts may be seen rarely in late stages of pulmonary sarcoidosis, adjacent to areas of dense fibrosis-these cysts may represent fibrotic cysts or para cicatricial emphysema. Classical associated chest findings of sarcoidosis include symmetric hilar and mediastinal lymphadenopathy (may be with calcifications) and perilymphatic distribution of micronodules and septal thickening (with upper and mid lung predominance); other less common findings are large irregular nodules (due to confluence of micronodules), patchy or confluent ground-glass densities, and areas of air-trapping, with features of interstitial fibrosis (showing upper lung predominance, in contrast to the common lower lung predominance of the common interstitial lung diseases).43,44

\section{Pulmonary Mesenchymal Cystic Hamartomas}

This extremely rare disease is a subtype of pulmonary hamartomas, characterised by multiple diffusely scattered large $(2$ to $6 \mathrm{~cm})$ thin-walled cysts and small (sub centimetric) nodules. Clinically these patients may be asymptomatic (with incidental lung finding) or may present with chronic cough and dyspnoea by third or fourth decade; but may present with haemoptysis or haemothorax, as the lesions are prone for haemorrhage. Although they are usually benign in nature, they can be fatal in few patients due to the complications like pulmonary haemorrhage, recurrent pneumothorax or malignant transformation. ${ }^{45,46}$ Findings that are helpful in differentiating the various cystic lung diseases with nodules as the other predominant associated CT lung abnormality are shown in Table 2.

\section{Other Rare Syndromic Cystic Lung Diseases}

Apart from LAM associated with tuberous sclerosis (where the lung cysts are the common abnormality), there are few hereditary syndromes like Marfan syndrome, neurofibromatosis type 1, Ehlers-Danlos syndrome and Proteus syndrome, where the presence of few lung cysts may be seen as one of the rare manifestation. ${ }^{32,47}$ 


\begin{tabular}{|c|c|c|c|}
\hline Diagnosis & Clinical features & Lung Cyst Features & Other Chest Abnormalities \\
\hline $\begin{array}{l}\text { Pulmonary Langerhans cell } \\
\text { histiocytosis }\end{array}$ & $\begin{array}{l}\text { Chronic dry cough and weight loss in cigarette } \\
\text { smoking young adults. }\end{array}$ & $\begin{array}{l}\text { Round to bizarre shaped small } \\
\text { cysts. }\end{array}$ & $\begin{array}{l}\text { Temporal heterogeneity: small stellate nodules, cavities and } \\
\text { cysts, with costophrenic angle sparing. }\end{array}$ \\
\hline Amyloidosis & $\begin{array}{l}\text { Chronic dry cough in Sjogren syndrome and } \\
\text { MALT lymphoma patients. }\end{array}$ & $\begin{array}{l}\text { Multiple variable sized cysts with } \\
\text { lower lung predominance. }\end{array}$ & $\begin{array}{l}\text { Small to large lung nodules (may with calcifications). May with } \\
\text { interlobular septal thickening and mediastinal } \\
\text { lymphadenopathy. }\end{array}$ \\
\hline Light chain deposition disease & $\begin{array}{l}\text { Chronic dry cough in patients with plasma cell } \\
\text { dyscrasias or autoimmune diseases. }\end{array}$ & Multiple, small, scattered cysts. & $\begin{array}{l}\text { Multiple, scattered, small to large sized, irregularly shaped lung } \\
\text { nodules and mediastinal lymphadenopathy. }\end{array}$ \\
\hline Follicular bronchiolitis & $\begin{array}{l}\text { Chronic dry cough in children with collagen } \\
\text { vascular or immune deficiency diseases. }\end{array}$ & $\begin{array}{l}\text { Few small, scattered cysts seen } \\
\text { rarely in these patients }\end{array}$ & $\begin{array}{l}\text { Diffuse tree-in-bud centrilobular ground glass nodules, } \\
\text { predominantly in the lower lobes. }\end{array}$ \\
\hline $\begin{array}{l}\text { Recurrent respiratory } \\
\text { papillomatosis }\end{array}$ & $\begin{array}{l}\text { Children with chronic hoarseness of voice, } \\
\text { stridor and respiratory distress. }\end{array}$ & Multiple cysts of variable sizes. & $\begin{array}{l}\text { Small to large lung nodules (may show cavitation), with posterior } \\
\text { lung predilection. }\end{array}$ \\
\hline Cystic tuberculosis & Chronic cough, fever and weight loss. & $\begin{array}{l}\text { Multiple variable sized, irregularly } \\
\text { shaped cysts. }\end{array}$ & $\begin{array}{l}\text { Tree-in-bud nodules, ground glass densities or consolidations; } \\
\text { upper and mid lung predominance. }\end{array}$ \\
\hline Cystic lung metastasis & History of primary malignancy elsewhere. & $\begin{array}{l}\text { Multiple variable sized cysts with } \\
\text { lower lung predominance. }\end{array}$ & $\begin{array}{l}\text { Cysts may be associated with variable sized lung nodules (few } \\
\text { may show internal haemorrhage). }\end{array}$ \\
\hline Sarcoidosis & $\begin{array}{l}\text { Chronic cough and dyspnoea or skin } \\
\text { abnormalities (like erythema nodosum) } \\
\text { without respiratory symptoms. }\end{array}$ & $\begin{array}{l}\text { Few irregularly shaped cysts, } \\
\text { adjacent to areas of dense fibrosis. }\end{array}$ & $\begin{array}{l}\text { Symmetric hilar and mediastinal lymphadenopathy, } \\
\text { perilymphatic micronodules and septal thickening (upper and } \\
\text { mid lung predominance). }\end{array}$ \\
\hline $\begin{array}{l}\text { Pulmonary mesenchymal cystic } \\
\text { hamartomas }\end{array}$ & Chronic cough and dyspnoea or haemoptysis & $\begin{array}{l}\text { Multiple scattered large ( } 2 \text { to } 6 \\
\text { cm) cysts. }\end{array}$ & Multiple scattered small (sub centimetric) lung nodules. \\
\hline
\end{tabular}

\section{CONCLUSIONS}

Although cystic lung diseases are uncommon, there is a wide spectrum of differential diagnosis (than previously described) and stepwise radiologic approach (in analysing the cyst characteristics and other associated lung abnormalities) using HRCT thorax, will help us in reaching (along with clinical and laboratory correlation) the final specific diagnosis in most of the patients, thereby optimising their treatment management, without the need of an invasive biopsy. HRCT thorax remains the single most useful imaging choice in the evaluation of the cystic lung diseases, with this simple stepwise radiologic approach being an easy way for the accurate diagnosis.

Financial or other competing interests: None.

Disclosure forms provided by the authors are available with the full text of this article at jemds.com.

\section{REFERENCES}

[1] Hansell DM, Bankier AA, MacMahon H, et al. Fleischner Society: glossary of terms for thoracic imaging. Radiology 2008;246(3): 697-722.

[2] Cantin L, Bankier AA, Eisenberg R. Multiple cystlike lung lesions in the adult. AJR Am J Roentgenol 2010;194(1):W1-11.

[3] Raoof S, Bondalapati P, Vydyula R, et al. Cystic lung diseases: algorithmic approach. Chest 2016;150(4):94565.

[4] Gafoor K, Patel S, Girvin F, et al. Cavitary lung diseases: a clinical - radiologic algorithmic approach. Chest 2018;153(6):1443-65.

[5] Litmanovich D, Boiselle PM, Bankier AA. CT of pulmonary emphysema--current status, challenges, and future directions. Eur Radiol 2009;19(3):537-51.

[6] Takahashi M, Fukuoka J, Nitta N, et al. Imaging of pulmonary emphysema: a pictorial review. Int J Chron Obstruct Pulmon Dis 2008;3(2):193-204.

[7] Cantin L, Bankier AA, Eisenberg RL. Bronchiectasis. AJR Am J Roentgenol 2009;193(3):W158-71.

[8] Stern EJ, Frank MS. CT of the lung in patients with pulmonary emphysema: diagnosis, quantification, and correlation with pathologic and physiologic findings. AJR Am J Roentgenol 1994;162(4):791-8.

[9] Johkoh T, Sakai F, Noma S, et al. Honeycombing on CT; its definition, pathologic correlation, and future direction of its diagnosis. Eur J Radiol 2014;83(1):27-31.

[10] Nishino M, Itoh H, Hatabu H. A practical approach to high - resolution CT of diffuse lung disease. Eur J Radiol 2014;83(1):6-19.

[11] Araki T, Nishino M, Gao W, et al. Pulmonary cysts identified on chest CT: are they part of aging change or of clinical significance? Thorax 2015;70(12):1156-62.

[12] Odev K, Guler I, Altinok T, et al. Cystic and cavitary lung lesions in children: radiologic findings with pathologic correlation. J Clin Imaging Sci 2013;3:60.

[13] Zylak CJ, Eyler WR, Spizarny DL, et al. Developmental lung anomalies in the adult: radiologic - pathologic correlation. Radiographics 2002;22 Spec No:S25-43.

[14] Beggs I. The radiology of hydatid disease. AJR Am J Roentgenol 2012;145(3):639-48.

[15] Polat P, Kantarci M, Alper F, et al. Hydatid disease from head to toe. Radiographics 2003;23(2):475-94.

[16] Johnson SR, Cordier JF, Lazor R, et al. European Respiratory Society guidelines for the diagnosis and management of lymphangioleiomyomatosis. Eur Respir J 2010;35(1):14-26.

[17] Pallisa E, Sanz P, Roman A, et al. Lymphangioleiomyomatosis: pulmonary and abdominal findings with pathologic correlation. Radiographics 2002;22 Spec No:S185-98.

[18] Agarwal PP, Gross BH, Holloway BJ, et al. Thoracic CT findings in Birt-Hogg-Dube syndrome. AJR Am J Roentgenol 2011;196(2):349-52.

[19] Escalon JG, Richards JC, Koelsch T, et al. Isolated cystic lung disease: an algorithmic approach to distinguishing Birt-Hogg-Dubé syndrome, lymphangioleiomyomatosis, and lymphocytic interstitial pneumonia. AJR Am J Roentgenol 2019:1-5.

[20] Hidalgo A, Falcó V, Mauleón S, et al. Accuracy of highresolution CT in distinguishing between Pneumocystis carinii pneumonia and non-Pneumocystis carinii pneumonia in AIDS patients. Eur Radiol 2003;13(5):1179-84.

[21] Kanne JP, Yandow DR, Meyer CA. Pneumocystis jiroveci pneumonia: high-resolution CT findings in patients with 
and without HIV infection. AJR Am J Roentgenol 2012;198(6):W555-61.

[22] Hartman TE, Primack SL, Swensen SJ, et al. Desquamative interstitial pneumonia: thin-section CT findings in 22 patients. Radiology 1993;187(3):787-90.

[23] Gupta N, Colby TV, Meyer CA, et al. Smoking-related diffuse cystic lung disease. Chest 2018;154(2):e31-5.

[24] Johkoh T, Müller NL, Pickford HA, et al. Lymphocytic interstitial pneumonia: thin - section CT findings in 22 patients. Radiology 1999;212(2):567-72.

[25] Sirajuddin A, Raparia K, Lewis VA, et al. Primary pulmonary lymphoid lesions: radiologic and pathologic findings. Radiographics 2016;36(1):53-70.

[26] Franquet T, Hansell DM, Senbanjo T, et al. Lung cysts in subacute hypersensitivity pneumonitis. J Comput Assist Tomogr 2003;27(4):475-8.

[27] Silva CIS, Churg A, MüLler NL. Hypersensitivity pneumonitis: spectrum of high-resolution CT and pathologic findings. AJR Am J Roentgenol 2007;188(2):334-44.

[28] Beigelman-Aubry C, Godet C, Caumes E. Lung infections: the radiologist's perspective. Diagn Interv Imaging 2012;93(6):431-40.

[29] Al-Saleh S, Grasemann H, Cox P. Necrotizing pneumonia complicated by early and late pneumatoceles. Can Respir J 2008;15(3):129-32.

[30] Brauner MW, Grenier P, Tijani K, et al. Pulmonary langerhans cell histiocytosis: evolution of lesions on CT scans. Radiology 1997;204(2):497-502.

[31] Abbott GF, Rosado-de-Christenson ML, Franks TJ, et al. From the archives of the AFIP: pulmonary langerhans cell histiocytosis. Radiographics 2004;24(3):821-41.

[32] Seaman DM, Meyer CA, Gilman MD, et al. Diffuse cystic lung disease at high-resolution CT. AJR Am J Roentgenol 2011;196(6):1305-11.

[33] Chew KM, Clarke MJ, Dubey N, et al. Nodular pulmonary amyloidosis with unusual, widespread lung cysts. Singapore Med J 2013;54(5):e97-9.

[34] Colombat M, Stern M, Groussard 0, et al. Pulmonary cystic disorder related to light chain deposition disease. Am J Respir Crit Care Med 2006;173(7):777-80.
[35] Pipavath SJ, Lynch DA, Cool C, et al. Radiologic and pathologic features of bronchiolitis. AJR Am J Roentgenol 2005;185(2):354-63.

[36] Ryu JH, Myers JL, Swensen SJ. Bronchiolar disorders. Am J Respir Crit Care Med 2003;168(11):1277-92.

[37] Ravin CE, Bergin D, Bisset GS, et al. Image interpretation session: 2000. Radiographics 2001;21(1):267-87.

[38] Marchiori E, Araujo Neto C, Meirelles GSP, et al. Laryngotracheobronchial papillomatosis: findings on computed tomography scans of the chest. J Bras Pneumol 2008;34(12):1084-9.

[39] Takemura T, Akiyama O, Yanagawa T, et al. Pulmonary tuberculosis with unusual cystic change in an immunocompromised host. Pathol Int 2000;50(8):672-7.

[40] Lee JY, Lee KS, Jung KJ, et al. Pulmonary tuberculosis: CT and pathologic correlation. J Comput Assist Tomogr 2000;24(5):691-8.

[41] Seo JB, Im JG, Goo JM, et al. Atypical pulmonary metastases: spectrum of radiologic findings. Radiographics 2001;21(2):403-17.

[42] Yogi A, Miyara T, Ogawa K, et al. Pulmonary metastases from angiosarcoma: a spectrum of CT findings. Acta Radiol 2016;57(1):41-6.

[43] Abehsera M, Valeyre D, Grenier P, et al. Sarcoidosis with pulmonary fibrosis: CT patterns and correlation with pulmonary function. AJR Am J Roentgenol 2000;174(6):1751-7.

[44] Criado E, Sánchez M, Ramírez J, et al. Pulmonary sarcoidosis: typical and atypical manifestations at highresolution CT with pathologic correlation. Radiographics 2010;30(6):1567-86.

[45] Van Klaveren RJ, Hassing HH, Wiersma-van Tilburg JM, et al. Mesenchymal cystic hamartoma of the lung: a rare cause of relapsing pneumothorax. Thorax. 1995;49(11):1175-6.

[46] Souza FF, Chen E. Mesenchymal cystic hamartoma of the lung: MRI and PET/CT appearance. J Thorac Imaging 2009;24(1):52-5.

[47] Karpman C, Aughenbaugh GL, Ryu JH. Pneumothorax and bullae in Marfan syndrome. Respiration 2011;82(3):21924. 